\title{
WANITA JEPANG DALAM PERSPEKTIF HISTORIS
}

\section{Oleh}

\section{Mudji Hartono*}

\begin{abstract}
Abstrak
Dalam sejarah Jepang yang panjang dapat diketahui proses perubahan tentang kedudukan dan fungsi wanita dalam kehidupan sosial dan politik. Semula wanita memiliki peranan yang sangat besar. Bentuk masyarakat pada awal perkembangan bangsa Jepang adalah berdasar matriarkal, kemudian dasar itu digantikan oleh patriarkal. Status wanita merosot tajam hingga pada derajat pelayan dalam masa feodalisme. Keadaan ini berubah lagi pada pasca Perang Dunia II seiring dengan kemajuan industri yang sangat cepat, kaum wanita senantiasa telah mendapatkan persamaan hak dengan kaum pria sehingga berani mengabaikan adat lama. Tradisi masyarakat yang dibentuk oleh ajaran Confusianisme asal Cina dan budaya feodal Jepang menyebabkan kedudukan dan fungsi wanita menjadi sangat lemah. Kebiasaan-kebiasaan lama lambat-laun mengalami erosi akibat kemajuan pendidikan pada kaum wanita.

Secara umum kondisi kaum wanita Jepang pada tahun 1970-an sudah banyak mengalami perubahan. Memang, sisa-sisa kebiasaan lama masih ada hingga kini dan masih menjadi ganjalan bagi peningkatan peranan wanita. Pembatasan-pembatasan terhadap kaum wanita belum hilang sepenuhnya, dan masih dapat dijumpai dalam kehidupan masyarakat. Tirai penyekat itu diyakini akan hilang dengan sendirinya. Sehingga pada waktunya kaum wanita juga memiliki kedudukan yang sejajar dengan kaum pria dalam bingkai budaya Jepang modern.
\end{abstract}

Kata kunci : Budaza feodal, Cina, Jepang, peranan, perubahan, dan wanita.

\section{A. Pendahuluan}

Pada abad ke-21 ini kajian wanita semakin marak dilakukan oleh para pakar dan pencinta ilmu-ilmu sosial, baik di dalam maupun di luar lingkungan perguruan tinggi. Dalam rangka mengangkat harkat dan martabat wanita serta menempatkan pada posisi yang proporsional, maka sudah sepantasnya masalah wanita diangkat sebagai sentral kajian, tidak terkecuali bidang sejarah. Sejarah yang memusatkan perhatiannya pada 
peranan wanita, emansipasi dan persamaan hak belum banyak ditulis sejarawan. Bagaimanapun dan di manapun kaum wanita turut memberikan andil dalam pelbagai bidang kehidupan masyarakat, apalagi di negara industri maju seperti Jepang.

Di Jepang, peranan wanita kiranya sudah dimulai sejak permulaan perkembangan masyarakat. Dalam naskah-naskah Cina kuno, Jepang disebut-sebut sebagai "Negeri Ratu”. Kata ratu ini sangat jelas menunjuk kepada sosok wanita pemimpin atau penguasa negeri. Maka istilah "Negeri Ratu” mengindikasikan bahwa di Jepang pada zaman kuno terdapat banyak negara kecil-kecil yang dipimpin oleh kaum wanita. Hal ini menunjukkan kedudukan dan peranan wanita dalam kehidupan masyarakat sangat besar. Pengertian “Negeri Ratu” menghilang dari catatan sejarah sejalan dengan perkembangan sosial dan politik Jepang. Peranan wanita itu mengalami perubahan akibat pengaruh ajaran Confusianisme yang sangat kuat dan berlakunya sistem feodal yang berlangsung sangat lama.

Kaum wanita pada awal sejarah Jepang memiliki kedudukan sosial dan politik yang tinggi. Mereka memiliki banyak kebebasan dalam kehidupan dan banyak menguasai kesusasteraan. Pada awal masa feodal, hak waris kaum wanita atas kekayaan masih diakui dan peranan mereka dalam sistem sosial dan politik masih dapat dikenali. Namun, kedudukan dan fungsi sosial kaum wanita berangsur-angsur berubah menjadi sangat kecil setelah sistem feodal bertambah kokoh. Selama modernisasi berlangsung, Jepang tidak pernah dipimpin oleh kaisar putri. Kehidupan kaum wanita belum banyak disentuh oleh modernisasi pada masa Restorasi Meiji. Lalu apakah kaum wanita tidak mempunyai peranan dalam industrialisasi ? Pemulihan peranan wanita dalam kehidupan sosial dan politik berjalan lambat karena adat yang merintangi sudah berakar kuat dalam 
masyarakat. Seiring dengan laju industrialisasi yang begitu kencang, terutama pada pasca

Perang Dunia II, maka kedudukan dan fungsi sosial wanita berubah menjadi lebih baik.

\section{B. Wanita dalam Pandangan Confusianisme}

\section{Wanita Jepang dalam Permulaan Sejarah}

Menurut naskah-naskah Cina, bahwa di Jepang dalam abad ke-3 terdapat banyak wanita yang memegang kepemimpinan negara. Hal ini sesuai benar dengan mitologi bangsa Jepang, yang menceriterakan asal usul garis kekaisaran berasal dari Dewi Matahari. Pada awal perkembangan sejarahnya, wilayah Jepang terbagi-bagi menjadi daerah-daerah kesukuan atau klen (disebut Uji) yang dipimpin oleh seorang kepala. Sebelum wilayah Jepang terintegrasi secara geopolitik menjadi sebuah kekaisaran ${ }^{1}$ terdapat $100 \mathrm{Uji}$ atau lebih yang masing-masing dipimpin oleh seorang wanita ataupun pria. Sistem sosial dan politik saat itu berpusat pada Uji (suku atau klen). Uji berdiri semi otonom, hubungan antara Uji yang satu dengan yang lain bersifat terbatas, yaitu hanya dalam bidang ekonomi perdagangan yang sempit.

Dalam masyarakat Jepang kuno terdapat suatu ciri yang jelas, yakni masyarakat didasarkan pada matriarkal (2). ${ }^{2}$ Namun, wanita dan pria memiliki hak yang sama dalam menduduki jabatan sebagai pemimpin politik dan agama (Shinto). Kepala Uji tidak saja berkedudukan sebagai pemimpin politik melainkan juga sebagai pemimpin agama sehingga tidak ada pemisahan antara istana dan kuil.

\footnotetext{
${ }^{1}$ Pengertian kekaisaran atau imperium adalah sekelompok negara atau teritorium di bawah sebuah negara yang mempersatukan beberapa wilayah dan rakyat di bawah seorang penguasa. Baca: Ahmad Syafii Maarif, “Kekaisaran Amerika”, dalam Republika, 14 Desember 2004, hlm. 12.

${ }^{2}$ Edwin O.Reischauer (1982). Manusia Jepang (a.b. Bakri Siregar).Jakarta: Sinar Harapan, hlm. 269.
} 
Pada abad ke-3 muncul Uji terbesar, yakni klen Yamato, yang menurut tradisi mitologi berasal dari garis keturunan Dewi Matahari. Pendiri klen Yamato mengklaim dirinya mendapat mandat untuk memimpin Jepang. Dengan alasan itulah dilakukan konsolidasi yang berhasil di hampir seluruh wilayah Jepang dan kemudian mengangkat dirinya sebagai kaisar pertama. Penyatuan Jepang dilanjutkan oleh klen Soga sehingga seluruh wilayah Jepang di bawah supremasinya (abad ke-6). Kepala-kepala Uji taklukan dijadikan pegawai kerajaan. Sepanjang sejarah tidak dijumpai seorang kaisar sebagai penakluk, orang-orang dekat kaisar adalah yang memegang kendali kekuasaan yang nyata.

Selama abad ke-7 dan 8 keadaan di Jepang ditandai adanya perubahan sosial dan politik sebagai akibat datangnya pengaruh budaya Cina secara besar-besaran, termasuk agama Budha dan ajaran Confusiansme. Ketika itu lahir kelas aristokrasi militer baru dan diikuti oleh munculnya hak-hak istimewa. Kemunduran Kerajaan Yamato menyebabkan konflik antarkeluarga aristokrasi militer. Elit-elit $U j i$ menyatakan dirinya sebagai kaum bangsawan sipil (Kuge). ${ }^{3}$ Perubahan sosial dan politik itu mengawali pudarnya peranan wanita dalam kepemimpinan di Jepang, dan pengertian "Negeri Ratu” menjadi samarsamar dan lama-lama tidak terdengar lagi. Hal ini bukan berarti tahta kekaisaran hanya diduduki oleh kaisar pria, melainkan terdapat pula kaisar putri yang memerintah Jepang.

Sejak permulaan kekaisaran Jepang sampai dengan tahun 1973 terdapat 127 orang kaisar yang memerintah, 11 orang di antaranya adalah wanita. Pada zaman Nara (abad ke-8) terjadi keseimbangan perbandingan jumlah kaisar wanita dan pria, yaitu $3: 4$. Namun, setelah itu pemimpin kekaisaran didominasi oleh kaisar pria. Pergantian kaisar

\footnotetext{
${ }^{3}$ Jonh Whitney Hall (1978). "The Yamato State and Spread of Chinese Influince”. Japan from Pre History to Modern Times. New York: Delta Book, hlm. 35-47.
} 
berdasarkan garis keturunan, maka pria dan wanita memiliki kesempatan yang sama dalam menjabat posisi teratas pada struktur politik dan sosial. Kontinuitas suksesi kekaisaran tidak ada masalah sehingga kekaisaran Jepang dikatakan terpanjang di dunia ini. Meskipun sesungguhnya di Jepang sering terjadi seorang kaisar yang diangkat segera digantikan oleh adik atau saudaranya karena alasan tertentu, atau mengundurkan diri sesudah bebas dari ritual-ritual pemerintah. Perbandingan jumlah kaisar wanita dan pria pada setiap periode dapat dilihat pada tabel 1 berikut.

Tabel 1.

Jumlah Kaisar Jepang Tahun 660 SM - 1973 M

\begin{tabular}{|c|c|c|c|c|}
\hline NO & PERIODE & KAISAR WANITA & KAISAR PRIA & JUMLAH \\
\hline 1 & $660 \mathrm{SM}-290 \mathrm{SM}$ & - & 7 & 7 \\
\hline 2 & $214 \mathrm{SM}-270 \mathrm{M}$ & 1 & 7 & 8 \\
\hline 3 & $313 \mathrm{M}-708 \mathrm{M}$ & 5 & 23 & 28 \\
\hline 4 & $712 \mathrm{M}-781 \mathrm{M}$ & 3 & 4 & 7 \\
\hline 5 & $794 \mathrm{M}-1185 \mathrm{M}$ & - & 32 & 32 \\
\hline 6 & $1192 \mathrm{M}-1336 \mathrm{M}$ & - & 17 & 17 \\
\hline 7 & $1338 \mathrm{M}-1477 \mathrm{M}$ & - & 7 & 7 \\
\hline 8 & $1489 \mathrm{M}-1600 \mathrm{M}$ & - & 4 & 4 \\
\hline 9 & $1603 \mathrm{M}-1867 \mathrm{M}$ & 2 & 12 & 14 \\
\hline 10 & $1868 \mathrm{M}-1911 \mathrm{M}$ & - & 1 & 1 \\
\hline 11 & $1912 \mathrm{M}-1925 \mathrm{M}$ & - & 1 & 1 \\
\hline 12 & $1926 \mathrm{M}-1973 \mathrm{M}$ & - & 116 & 127 \\
\hline \multicolumn{2}{|c|}{ Jumlah } & 11 & 1 \\
\hline
\end{tabular}

Sumber: Taro Sakamoto (1980). Jepang Dulu dan Sekarang.Yogyakarta: Gama Press,hlm. 61-77.

Tabel di atas hanyalah sekedar untuk menunjukkan perbandingan jumlah kaisar putri dan pria, dan tidak termasuk jumlah pemimpin Uji karena keterbatasan sumber data. Setidaknya data itu dapat memberikan petunjuk bahwa wanita Jepang memiliki peranan penting pada zaman kuno. Kaum wanita masih memiliki kebebasan di dalam istana 
Heian (sekarang: Kyoto) dan bahkan peranannya masih cukup besar hingga pada awal masa feodal. ${ }^{4}$ Wanita memiliki peran penting bagi suatu keluarga (klen) yang hendak merebut pengaruh politik di istana, yaitu melalui perkawinan politik. Cara ini ditempuh karena dalam pandangan bangsa Jepang, kaisar adalah sebagai orang suci dan kramat, sehingga pemberontakan untuk merebut kekuasaan dianggap tabu dan tidak dibenarkan oleh rakyat. Peperangan adalah cara lain yang dilakukan oleh keluarga-keluarga aristokrasi militer tetapi bukan untuk memerangi kaisar, melainkan untuk memperluas hegemoni, agar dapat memiliki pengaruh politik dan dekat dengan kaisar. Dengan demikian perkawinan politik merupakan cara yang sangat strategis, dan wanita dipakai sebagai alat politik untuk menciptakan garis keturunan kaisar. Seorang anak keturunan dari hasil perkawinan antara kaisar dengan seorang wanita dari suatu keluarga (seperti keluarga Fujiwara) memiliki hak waris dalam kekuasaan kerajaan. Pada umumnya selama periode Fujiwara, anak dari keluarga kerajaan dijadikan kaisar dan dipaksa untuk mengawaini perempuan dari keluarga Fujiwara. Ketika kaisar sudah dewasa, posisinya digeser dan digantikan oleh seorang anak kecil dari keluarga terdekat yang pada gilirannya dikawinkan dengan perempuan dari keluarga Fujiwara. Para anggota keluarga dapat menikmati kekuasaan politik, yaitu sebagai Mangkubumi dalam pemerintahan kaisar-kaisar kecil tersebut.

Pada akhir periode Heian di mana Jepang dilanda perang antarkeluarga aristokrasi militer yang berkepanjangan, maka kedudukan wanita dalam kehidupan sosial dan politik mengalami pergeseran. Adanya pandangan bahwa secara fisik kaum wanita tidak cukup kuat dalam peperangan adalah mengurangi peranan wanita. Sehingga konflik bersenjata

\footnotetext{
${ }^{4}$ Edwin O. Reischauer, loc.cit.
} 
merupakan satu penyebab mundurnya status wanita; hak hidupnya dilanggar, hak pendidikan anak perempuan tidak terpenuhi, hak untuk tidak didiskriminasi dan tidak mengalami kekerasan justru meningkat. $^{5}$ Di samping itu periode ini adalah masa transisi ke budaya gaya aristokrasi yang feodalistik, ini berarti status laki-laki meningkat bersamaan dengan naiknya kekuasaan golongan samurai. Sebaliknya status wanita merosot dan lambat laun dikeluarkan dari struktur feodal dan menerima peran yang tidak penting serta hanya sebagai pelengkap kaum pria. ${ }^{6}$

\section{Wanita Jepang dalam Zaman Feodal dan Zaman Meiji}

Sistem feodal di Jepang berlangsung sejak abad ke-12 hingga pertengahan abad ke-19, dengan ditandai munculnya keluarga-keluarga aristokrasi militer yang memiliki kekuasaan di daerah-daerah. Pada periode Edo berkembang sistem feodal terpusat yang merupakan masa kekuasaan kaum ksatria (samurai) di bawah pimpinan Shogun Tokugawa. Pemerintahan militer mendasarkan pada ajaran filsafat Confusius yang berintikan pendidikan moral. Ajaran Confusius dan Shinto digunakan untuk membuat pedoman hidup samurai, atau kode etik samurai yang disebut Bushido.

Selama masa feodal kedudukan kaisar hanya sebagai pemimpin tertinggi agama dan lambang persatuan bangsa, kekuasaan dalam politik diambilalih oleh shogun. Telah disebut di atas bahwa tahta kekaisaran Jepang didominasi oleh kaum pria. Antara tahun 794 sampai dengan tahun 1973 hanya ada dua orang kaisar wanita yang memerintah Jepang. Ada dua periode panjang dalam pemerintahan Jepang tanpa kaisar wanita, yaitu tahun 794 - 1600 dan tahun 1868 - 1973. Jabatan kaisar wanita yang terakhir dipegang

\footnotetext{
${ }^{5}$ Saparinah Sadli, “Tujuan Pembangunan Millenium (Millenium Development Goals/MDGs Perspektif Jender”, Pidato Penerima Anugerah Hamengku Buwono IX Tahun 2004, 20 Desember 2004.

${ }^{6}$ Edwin O. Reischauer, op.cit.,hlm. 270.
} 
oleh Gosakuremachi (1762-1770). Adanya dua kaisar wanita itu membuktikan bahwa hak waris wanita untuk menjadi kaisar masih diakui selama masa feodalisme (16031867). Nama-nama kaisar putri dapat dilihat pada tabel 2 berikut ini.

Tabel 2.

Kaisar Wanita di Jepang

\begin{tabular}{|c|c|c|c|c|}
\hline Zaman & Tahun & Nama Kaisar & Peristiwa & Keterangan \\
\hline Keb.Yayoi & 192 & Jingu & $\begin{array}{l}\text { Budaya Asia mulai } \\
\text { masuk Jepang }\end{array}$ & \\
\hline Keb.Tumulus & 592 & Suiko & $\begin{array}{l}\text { Berdirinya Hokoji \& } \\
\text { Shitennoji }\end{array}$ & \\
\hline Keb.Tumulus & 642 & Kogyoku & $\begin{array}{l}\text { Mangkubumi Soga- } \\
\text { no Iruka }\end{array}$ & \\
\hline Keb.Tumulus & 655 & Saimei & - & \\
\hline Keb.Tumulus & 686 & Jito & & \\
\hline Keb.Tumulus & 701 & Genmei & $\begin{array}{l}\text { UUD Taiho } \\
\text { Konsolidasi sistem } \\
\text { kekuasaan terpusat }\end{array}$ & \\
\hline Nara & $\begin{array}{l}715 \\
749 \\
764\end{array}$ & $\begin{array}{l}\text { Gensho } \\
\text { Koken } \\
\text { Shotoku }\end{array}$ & $\begin{array}{l}- \\
- \\
-\end{array}$ & \\
\hline Edo & $\begin{array}{l}1629 \\
1762\end{array}$ & $\begin{array}{l}\text { Meisho } \\
\text { Gosakuremachi }\end{array}$ & $\begin{array}{ll}\text { Larangan } & \text { wanita } \\
\text { bermain } & \text { dalam } \\
\text { drama kabuki } & \\
- & \end{array}$ & $\begin{array}{l}\text { Pemerintahan } \\
\text { Shogun Iemitsu } \\
\text { PemerintahanShogun } \\
\text { Ieharu }\end{array}$ \\
\hline
\end{tabular}

Sumber: Taro Sakamoto (1980). Jepang Dulu dan Sekarang. Yogyakarta: Gama Press,hlm.61-77.

Ketika itu mulai terjadi perubahan peranan wanita yang disebabkan oleh kuatnya pengaruh ajaran Confusianisme, dan juga adanya pandangan tentang kekuatan fisik wanita tidak cocok untuk menjadi samurai (tentara) yang tugas utamanya berperang. Ajaran Confusius sebagai warisan masyarakat patriarkal yang menunjukkan dominasi kaum pria Cina, membatasi kebebasan kaum wanita dan memaksa mereka tunduk kepada kaum pria. Dalam ajaran Confusius antara lain dikatakan bahwa istri harus menghormati 
suami; seorang istri diharapkan untuk mengabdikan dirinya tanpa memikirkan kepentingan sendiri guna kesejahteraan keluarga sang suami, dan istri lebih penting untuk melahirkan anak dan objek cinta.

Sistem politik isolasi (sakoku) masa Shogun Tokugawa turut berpengaruh pada kedudukan dan peranan wanita. Pembatasan kekuasaan kaisar itu sekaligus memperkecil peranan kaum wanita, karena kekuasaan golongan samurai semakin besar. Posisi kaum wanita dalam hierarki sosial sangat rendah, peranan wanita hanyalah mengabdi kepada kaum pria. Kaum wanita dididik agar taat setia kepada keluarga, terutama orang tua. Wanita dari golongan bangsawan diajarkan tentang etika tradisional agar dapat melayani tamu dengan baik. ${ }^{7}$ Fungsi sosial kaum wanita dihargai sebagai kaum ibu yang karena melahirkan anak, dan membesarkan para pengganti kepala keluarga. Ajaran untuk kaum wanita, sebagaimana diungkapkan dalam buku: The Greater Learning for Women, adalah menekankan derajat kaum wanita lebih rendah daripada pria. ${ }^{8}$

Kedudukan dan fungsi sosial kaum wanita tersebut sangat jelas terdapat di masyarakat kalangan menengah ke atas, sedangkan di pedesaan masih dapat dilihat peranan wanita tani dalam membantu mencari nafkah. Kaum wanita tani tetap penting sebagai teman kerja kaum pria di ladang-ladang dan karena itu lebih memiliki kebebasan individual daripada di kalangan atas. ${ }^{9}$ Pada zaman modern terjadi perubahan sosial dalam masyarakat desa, wanita tani menjadi tenaga pokok di pertanian karena kaum pria lebih senang bekerja di pabrik, baik sebagai buruh tetap maupun musiman. ${ }^{10}$ Meskipun

Abdullah Zakaria Ghazali (et.al.).(2000). Sejarah Asia Tenggara,Asia Selatan Dan Asia Timur 1800-1963. Kuala Lumpur: Fajar Bakti Sdn.Bhd. hlm. 323.

${ }^{8}$ (8). Masu Okamura (1983). Peranan Wanita Jepang (a.b. Emy Kuntjoro-Jakti). Yogyakarta: Gadjah Mada University Press. hlm. 1.

${ }^{9}$ Edwin O.Reischauer, loc.cit.

${ }^{10}$ Ibid. hlm.277-278. 
demikian keluarga petani hanya bisa meningkatkan status sosial yang relatif karena umumnya anak petani enggan mendapat jodoh dengan anak petani. Di samping itu tingkat pendidikan mereka umumnya masih rendah dan jarang yang mencapai perguruan tinggi.

Walaupun sesungguhnya tingkat melek huruf kaum wanita sejak zaman feodal sudah $15 \%$ berbanding $45 \%$ kaum pria, ${ }^{11}$ namun umumnya anak perempuan tidak bersekolah tetapi berlatih di rumah dalam hal pekerjaan rumah dan etika. Jumlah wanita yang berpendidikan mulai meningkat pada akhir pemerintahan Shogun Tokugawa, terutama di Terakoya (sekolah model biara untuk rakyat). Materi yang diajarkan di sekolah-sekolah untuk wanita terbatas pada moral dan etika sesuai dengan kodrat wanita. Buku Jitsugokyo merupakan pedoman, yang isinya menekankan kewajiban wanita sebagai anak, istri dan ibu. Inti ajarannya adalah kedudukan wanita rendah dan kewajibannya yang terpenting adalah patuh pada orang tua (ketika masih anak-anak), patuh pada suami (setelah menikah), patuh pada anak tertua (setelah tua), dan patuh pada mertua wanita (ketika hidup berumah tangga). Setelah wanita mempunyai suami maka baginya yang penting dapat melahirkan anak, karena menjadi ibu berarti memperoleh status. Seorang istri yang tidak dapat menghasilkan anak akan berakibat kedudukannya dalam keluarga goyah, kemungkinan disisihkan dan tidak akan dapat menjadi mertua. ${ }^{12}$

Pada masa Meiji, pengaruh pendidikan Barat dengan cepat meluas hingga dianggap melampaui batas kewajaran, maka kaisar menginstruksikan agar pendidikan kembali pada prinsip-prinsip Confusianisme. Maklumat Kerajaan tahun 1890 menjadi

\footnotetext{
${ }^{11}$ Sayidiman Suryohadiprojo (1982). Manusia Dan Masyarakat Jepang Dalam Perjuangan Hidup. Jakarta : UI Press, hlm. 25.

${ }^{12}$ Ruth Benedict (1982). Pedang Samurai dan Bunga Seruni, Pola-Pola Kebudayaan Jepang. Jakarta : Sinar Harapan, hlm. 267.
} 
pedoman arah pendidikan Jepang bagi semua perilaku politik dan kemasyarakatan Jepang. Sekolah-sekolah dasar, sekolah menengah dan lembaga-lembaga militer menanamkan dengan kuat kepercayaan tentang kekuasaan absolut kaisar. ${ }^{13}$ Propaganda mitos politik tentang kesucian dan kekeramatan lembaga kekaisaran didengungkan. ${ }^{14}$ Meiji Tenno dihormati oleh rakyat bagaikan dewa, meskipun menurut Jenderal Nogi dan istrinya, penghormatan itu bersifat semu. ${ }^{15}$ Kaisar Mutsuhito menekankan dasar NeoConfusianisme sebagai dasar ideologi negara. ${ }^{16}$ Kebijakan kaisar mengenai birokarasi berdasarkan ajaran Confusius, akibatnya terjadi diskriminasi karena seseorang yang duduk dalam pemerintahan diutamakan orang yang berpendidikan, bukan hanya mendapatkan jabatan dari keturunan. ${ }^{17}$ Jabatan-jabatan tinggi negara, baik sipil maupun militer, diisi oleh kaum pria yang berpendidikan Barat, terutama berasal dari klen Chosu dan Satsuma. Kelihatannya dalam sistem status mulai terbuka dengan diterapkannya jalur achievement, namun mobilitas sosial bagi kaum wanita tetap saja tertutup. Diskriminasi terjadi karena pendidikan bagi kaum wanita masih terbatas, apalagi hanya sedikit peluang bagi wanita untuk mengenyam pendidikan pada tingkat perguruan tinggi.

Antara 1870-1900 telah didirikan sekolah-sekolah putri dari tingkat dasar hingga perguruan tinggi, dan dimulainya sistem pendidikan modern. Namun demikian bagi anakanak perempuan setelah tamat sekolah wajib 6 tahun hanya diberikan kesempatan melanjutkan ke sekolah menengah untuk wanita (4 atau 5 tahun), sedangkan untuk anak laki-laki mendapat kesempatan memilih ke sekolah menengah (5 tahun) atau ke kejuruan.

\footnotetext{
${ }^{13}$ Kano Osamu et.al. Individu dan Kekuasaan. Jakarta: Grasindo, 1995, hlm. 61.

${ }^{14}$ Kenneth B. Pyle,hlm. 264-265.

${ }^{15}$ David H. James. The Rise and Fall of The Japanese Empire. London: George Allen \& Unwin LTD, hlm 156 dan 158.

${ }^{16}$ Abdullah Zakaria Ghazali, loc.cit.

${ }^{17}$ Edwin O. Reischauer, op.cit., hlm.91-92.
} 
Setelah taraf ini, untuk wanita hanya dapat meneruskan ke sekolah khusus (3 atau 4 tahun), sedikit sekali yang dapat melanjutkan ke universitas. Bagi anak laki-laki diberikan kesempatan memilih 3 sekolahan, yaitu sekolah khusus (3 atau 4 tahun), universitas (5 tahun) atau sekolah menengah (3 tahun) kemudian ke universitas (3 tahun).

Selain itu kurikulum sekolah untuk wanita berorientasi ke arah pendidikan calon ibu rumah tangga, berbeda dengan tujuan pendidikan untuk anak-anak laki-laki yang mengutamakan masalah-masalah praktis. Oleh karena itu ilmu pengetahuan yang dimiliki kaum wanita lebih sempit daripada kaum pria. ${ }^{18}$ Akibatnya jabatan dalam birokrasi Jepang diduduki oleh kaum pria. Pekerjaan di perusahaan-perusahaan dikerjakan oleh kaum pria, sedangkan kaum wanita mengerjakan pekerjaan rumah tangga.

\section{Kebangkitan Wanita Jepang}

Pasca Perang Dunia II, kaum wanita Jepang mulai bangkit untuk meningkatkan peranannya dalam bidang sosial dan politik. Peranan kaum ibu telah banyak berubah, walaupun dibandingkan dengan negara-negara industri yang lain termasuk belum begitu luas. Kaum wanita sudah mulai meninggalkan adat lama yang berasal dari ajaran Confusianisme. Menurut Okamura “Zaman wanita yang cerdas sudah tiba”. ${ }^{19}$ Pendidikan kaum wanita sudah berkembang dan wanita karier mengalami peningkatan. Wajib belajar telah berubah dari 6 tahun menjadi 9 tahun. Walaupun wanita yang sampai ke tingkat pendidikan tinggi prosentasenya sangat kecil, dan banyak yang berguguran, namun wanita terdidik telah mengalami peningkatan.

\footnotetext{
${ }^{18}$ Tentang diskriminasi pendidikan, baca : J.K. Fairbank (et.al.) (1973). East Asia: Tradition and Transformation. London: George Allen \& Unwin, hlm. 534.

${ }^{19}$ Masu Okamura, op.cit., hlm.xv.
} 
Perubahan sosial yang tajam terjadi seiring dengan perkembangan industri yang cepat, situasi itu mempengaruhi kedudukan dan fungsi wanita dalam masyarakat. Kesamaan hak antara pria dan wanita dalam hubungannya dengan politik, ekonomi dan sosial dijamin undang - undang yang berlaku sejak 1947. Diskriminasi tidak dibenarkan UU, dan wibawa kaum wanita diberikan lebih besar daripada sebelumnya. UU memberikan persamaan hukum bagi kaum wanita secara sepenuhnya, yaitu meliputi soal perkawinan, perceraian, hak milik, warisan, pilihan tempat tinggal, dan soal keluarga yang lain.

Kaum wanita tidak lagi terkungkung di dalam urusan rumah tangga, mereka sudah mulai mengerjakan pekerjaan di luar rumah tangga, seperti di bidang industri, pertanian, perikanan, dan kehutanan. Di kota-kota besar Jepang, wanita mengerjakan pekerjaan industri rumah di rumah mereka sendiri. ${ }^{20}$ Pembatasan-pembatasan terhadap wanita memang masih dapat dijumpai pada pola pengupahan, kenaikan pangkat dan masa kerja. Pada perusahaan swasta, dalam pekerjaan yang sama upah wanita tidak sampai 50\% dibandingkan pekerja pria. Wanita yang menangani manajemen atau pekerjaan yang bertanggung jawab sangat sedikit, ini dipakai sebagai alasan untuk memberi gaji rendah kepada pekerja wanita. Pegawai negeri wanita dinilai lebih lamban dalam kenaikan pangkat dan dianjurkan pensiun pada usia muda dibandingkan pegawai pria. ${ }^{21}$

Titik terang peranan wanita bagaimanapun sudah tampak, kaum wanita telah hadir di bidang-bidang yang sebelumnya tertutup; di bidang seni melahirkan seniwatiseniwati kelas dunia, dan di bidang akademik bermunculan ilmuwan-ilmuwan wanita. Keadaan itu tidak terlepas dari adanya UU tentang persamaan hak dan semakin

\footnotetext{
${ }^{20}$ Ruth Benedict, op.cit., hlm. 101.

${ }^{21}$ Sayidiman Suryohadiprojo, op.cit., hlm.170.; Lihat juga: Masu Okamura, op.cit.,hlm. 35.
} 
banyaknya peluang yang tersedia, termasuk waktu bagi kaum wanita untuk mengerjakan pekerjaan di luar rumah tangga. Beban tugas rumah tangga menjadi semakin ringan setelah Revolusi Konsumsi, sebab terdapat kecenderungan untuk menggunakan barangbarang industri tahan lama. Ikatan istri dengan mertua semakin kendor setelah adat tinggal bersama mertua istri diabaikan oleh pasangan suami-istri, dan mereka bebas menentukan tempat tinggal di luar keluarga. Perkawinan didasarkan saling cinta dan semakin banyak pernikahan dilaksanakan lewat aturan hukum sipil yang berlaku, bukan melalui hukum adat. Otoritas istri di dalam keluarga bertambah besar, bahkan kadang ada yang melampaui otoritas suami. ${ }^{22}$ Namun, seorang istri akan kehilangan otoritasnya jika tidak dapat melahirkan anak. ${ }^{23}$ Keluarga Jepang modern berpusat pada ibu dan didominasi oleh ibu. Wanita mempunyai daya kemauan dan kekuatan psikologis daripada pria. Pengasuhan dan pendidikan anak dalam keluarga dilakukan oleh ibu. ${ }^{24}$ Di luar lingkungan keluarga, kaum wanita melakukan berbagai aktivitas di organisasi-organisasi sosial dan politik. Perkumpulan-perkumpulan kaum ibu yang didirikan, antara lain : Konperensi Kaum Ibu dan Liga Kaum Istri. Organisasi yang bergabung di dalam gerakan yang menyebut Konperensi Kaum Ibu adalah organisasi buruh wanita, organisasi wanita dan kelab-kelab wanita. Gerakan ini bersifat nasional dan mencakup seluruh lapisan masyarakat. Tujuan gerakan adalah untuk perdamaian dunia dan perlindungan anak, karena itu gerakannya meliputi anti percobaan senjata nuklir, anti persenjataan kembali dari Jepang, pemberantasan folio, dan pornografi. Liga Kaum Istri melancarkan gerakan

\footnotetext{
${ }^{22}$ Masu Okamura, ibid., hlm. 21.

${ }^{23}$ Ruth Benedict, op.cit.,hlm. 267.

${ }^{24}$ Edwin O.Reischauer, op.cit.,hlm. 275-276.
} 
perlindungan konsumen, pendirian koperasi dan sebagainya. Kaum wanita sudah berani mengkritik pemerintah daerah dalam penganggaran pembangunan kota.

Persamaan hak di bidang politik sudah ada sejak tahun 1946, yaitu kaum wanita memiliki hak memilih dan dipilih dalam pemilihan umum. Hasil pemilihan umum tahun 1946 ada 39 wanita yang dipilih dari 83 calon wanita. Mereka itu juga menjadi anggota parlemen dan dewan-dewan perwakilan rakyat daerah serta dalam tiap tingkat administrasi pemerintahan. Partisipasi wanita mengalami penurunan sehingga tahun 1971 hanya terdapat 8 wanita yang duduk dalam House of Representatives dan 13 wanita yang ada dalam House of Counsillors. Dasawarsa berikutnya baru diketemukan seorang Duta Besar wanita dan kepala departemen di universitas yang dijabat oleh seorang wanita. ${ }^{25}$ Namun secara umum kesadaran politik wanita masih rendah, dan partisipasi wanita belum menggembirakan terutama dalam pengambilan keputusan pada taraf nasional.

\section{Kesimpulan}

Dalam perspektif historis, wanita Jepang mengalami perubahan kedudukan dan peranannya dalam pelbagai aspek kehidupan masyarakat. Tradisi Jepang asli menempatkan kaum wanita pada kedudukan sosial dan politik yang tinggi. Peranan kaum wanita itu mengalami perubahan sebagai akibat pengaruh budaya Cina, khususnya ajaran Confusianisme. Dalam proses sejarah yang panjang, sistem matriarkal berganti menjadi patriarkal. Munculnya sistem feodal bersama-sama dengan ajaran Confusianisme menyebabkan kedudukan dan fungsi kaum wanita sangat terpuruk, baik dalam bidang sosial, ekonomi maupun politik.

\footnotetext{
${ }^{25}$ Sayidiman Suryahadiprojo, loc.cit.
} 
Berakhirnya feodalisme Jepang dilanjutkan dengan modernisasi oleh Meiji Tenno, dan perubahan yang luar biasa terjadi tetapi status dan fungsi kaum wanita belum banyak berubah. Kedudukan sosial dan politik kaum wanita baru ditingkatkan dengan lebih baik setelah Perang Dunia II. Peranan wanita Jepang sudah semakin besar dengan mengikuti proses industrialisasi yang cepat.

\section{DAFTAR PUSTAKA}

Abdullah Zakaria Ghazali (et.al.).(2000). Sejarah Asia Tenggara,Asia Selatan Dan Asia Timur 1800-1963. Kuala Lumpur: Fajar Bakti Sdn.Bhd.

Ahmad Syafii Maarif, “Kekaisaran Amerika”, dalam Republika, 14 Desember 2004.

Benedict, Ruth. (1982). Pedang Samurai dan Bunga Seruni, Pola-Pola Kebudayaan Jepang. Jakarta : Sinar Harapan.

Fairbank, Jonh K. (et.al.) (1973). East Asia: Tradition and Transformation. London: George Allen \& Unwin.

Hall, Jonh Whitney. (1978). “The Yamato State and Spread of Chinese Influince”. Japan from Pre History to Modern Times. New York: Delta Book.

James, David H. The Rise and Fall of The Japanese Empire. London: George Allen \& Unwin LTD, hlm 156 dan 158.

Okamura, Masu. (1983). Peranan Wanita Jepang. (terj. Emy Kuntjoro-Jakti).Yogyakarta: Gadjah Mada University Prees.

Osamu, Kano. (et.al.) (1995). Individu dan Kekuasaan. Jakarta: Grasindo.

Reischauer, Edwin O. (1982). Manusia Jepang. Jakarta: Sinar Harapan.

Sakamoto, Taro. (1980). Jepang Dulu dan Sekarang. Yogyakarta: Gama Press.

Saparinah Sadli, “Tujuan Pembangunan Millenium (Millenium Development Goals/ MDGs Perspektif Jender”, Pidato Penerima Anugerah Hamengku Buwono IX Tahun 2004, 20 Desember 2004).

Sayidiman Suryohadiprojo.(1982). Manusia Dan Masyarakat Jepang Dalam Perjuangan Hidup. Jakarta : UI Press. 